\title{
Os Aspectos da Reabilitação e Modernização do Edifício do Hospital Escola São Francisco de Assis (HESFA/UFRJ)
}

SILVA Camilla de Abreu $\mathrm{e}^{1}$, QUALHARINI Eduardo Linhares ${ }^{2}$

'Programa de Engenharia Urbana - PEU/POLI/UFRJ

${ }^{2}$ Escola Politécnica da UFRJ - POLI/UFRJ

Informações do Artigo

Histórico:

Recebimento: Setembro 2018

Revisão: Setembro 2018

Aprovação: Setembro 2018

Palavras-chave:

Reabilitação de Edifícios

Restauração de Patrimônio

Histórico

Hospital Escola São Francisco

de Assis (HESFA)

\begin{abstract}
Resumo:
Inaugurado por Dom Pedro II em 1879, o Asylo da Mendicidade atualmente é conhecido como Hospital Escola São Francisco de Assis, que pertence a Universidade Federal do Rio de Janeiro (UFRJ). Trata-se de uma construção tombada pelo Instituto do Patrimônio Histórico e Artístico Nacional (IPHAN) e que, ainda hoje, atende pacientes cadastrados no Sistema Único de Saúde (SUS). Contudo, poucos recursos são empregados em sua manutenção, com comprometimento de estruturas, insuficiência de sistemas prediais elétricos, hidráulicos e obliteração tecnológica. Assim, a UFRJ, através do Escritório Técnico da Universidade (ETU), iniciou ações de reabilitação do edifício, contemplando a atualização tecnológica, a resolução de problemas de engenharia estrutural e a restauração de elementos históricos. Todavia, empecilhos culminaram no embargo momentâneo da obra, cuja origem foi no atendimento a legislação, normas técnicas, custos e investimentos. Por esta razão, o presente estudo é uma análise crítica para desvendar as dificuldades trazidas pelas diretrizes, legislações e normas de restauração de patrimônio para a preservação de edifícios. Em adição, este trabalho busca reconhecer o modo como a preservação do bem não significa impedimento a sua modernização e revitalização.
\end{abstract}

\section{Introdução}

A reabilitação de edifícios é uma prática amplamente adotada em outros países, porém nem sempre bem recebida no Brasil. Contudo, no Rio de Janeiro, após o advento de intervenções bem sucedidas, como a reabilitação do edifício sede da extinta companhia aérea "Varig" e o rebranding para integração ao projeto do Museu de Arte do Rio (MAR), ficou caracterizado que a principal dificuldade de atuação na área de reabilitação é a conciliação do programa de intervenções, que exige um minucioso detalhamento, sendo interrompido pelas muitas interfaces que serão necessárias para atender aos aspectos de arquitetura histórica diferenciada.

Este é caso do Hospital Escola São Francisco de Assis (HESFA), que é o único remanescente sul americano de uma arquitetura neoclássica panóptica, sendo tombado pelo Instituto do Patrimônio Histórico e Artístico Nacional (IPHAN). 
O HESFA é uma instituição considerada como centro de referência nacional na pesquisa e tratamento de pessoas portadoras do vírus HIV, atendendo a 20 mil pacientes, por mês, das mais diversas faixas etárias. No entanto, tal sucesso não pode ser creditado à sua arquitetura, instalações e infraestrutura, pois seus anexos foram construídos irregularmente e a edificação tem inexistência de manutenção preventiva ou sequer corretiva, além de apresentar depredações causadas por vandalismo, com obsolescência tecnológica e com inoperabilidade em diversas alas por insuficiência de capacidade de suas instalações prediais.

Em 2014, Monteiro (2014) caracterizou o abandono de um bem tombado como uma questão controversa, pois espera-se que haja a conscientização da necessidade de sua preservação e continuidade através de seu tombamento, complementando que os imóveis patrimoniais do país não receberiam os adequados investimentos para restauro, sendo a manutenção preventiva preterida por aquelas de caráter restaurativo urgente, sem resguardar os aspectos que comporiam a identidade histórica. Em face das dificuldades enfrentadas por edifícios tombados para sua preservação e restauração, este estudo apresenta uma análise de normas e práticas de restauração de patrimônio para os desafios impostos na viabilização da reabilitação do HESFA.

\section{Restauração de Patrimônio Histórico: Estado Atual}

Souza et al (2002) argumentaram que, acrescidos aos longos anos de abandono e falta de manutenção de suas instalações, a situação precária do Hospital Escola São Francisco de Assis (HESFA) foi potencializada por sua reativação apressada para ser um centro de referência médico, pela urgência de uma calamidade pública, conforme exposto no item anterior. Desta maneira, o espaço útil da instituição encontra-se ocupado em apenas $40 \%$ de sua área total, uma vez que muitas de suas instalações encontram-se desfiguradas e/ou em necessidade de conciliar restauração com reparos imediatos.
Em adição, Monteiro (2014) ressaltou que a falta de investimentos para a restauração dos edifícios históricos, durante décadas, acarretou em uma expressiva degradação de suas benfeitorias. Sem a adequada manutenção, as referidas não foram capacitadas para comportar as novas tecnologias de maquinários e equipamentos médicos, conduzindo no caso do HESFA, a que diversas alas perdessem seu uso e consequentemente fossem abandonadas. Neste contexto, Kühl (1998) argumentou que "a reutilização do bem é o meio mais eficaz para garantir a sua preservação, pois um monumento sem uso se deteriora rapidamente enquanto aquele mantido em funcionamento pode durar séculos".

Sob a perspectiva da a arquitetura original do HESFA, esta sofreu a adição de "construções espúrias", acrescentadas ao longo dos anos e motivadas por necessidades de novos serviços de saúde e/ou ocupações irregulares, para as quais deveria existir um processo de restauração, que incluiria a demolição e recuperação da integridade do conjunto arquitetônico. A seguir, o conjunto dos prédios pertencentes ao HESFA Figura 1.

Figura 1 - Evolução do Conjunto do HESFA durante sua História.

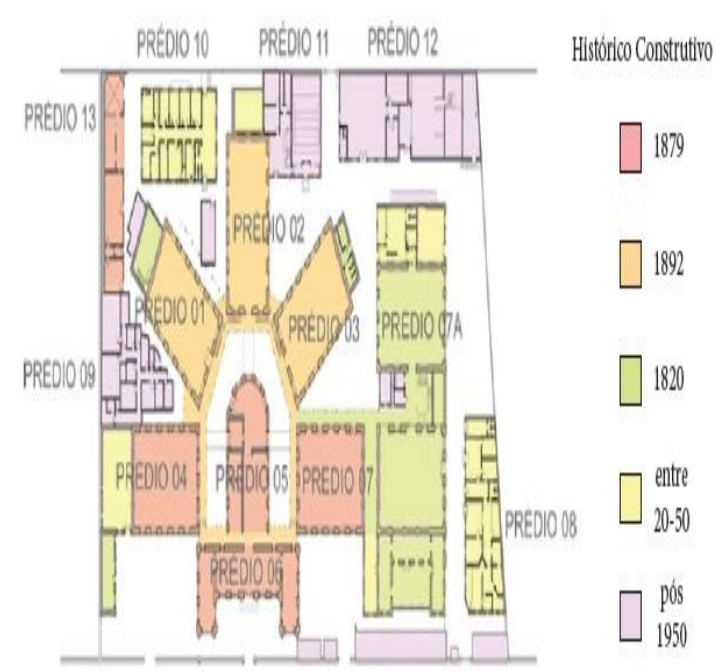

Fonte: UFRJ (2013), apud Monteiro (2014)

\section{Gestão, Financiamento e Custos}

Desde 2004, a administração do HESFA busca por recursos para a realização de obras de restauração de suas instalações, porém tem encontrado dificuldades na obtenção de subsídios. Somente após a publicação do "Plano Diretor UFRJ 2020", aprovado pelo Conselho 
Universitário em 05 de Novembro de 2009, foi possível a autorização para disponibilização de um fundo visando a recuperação do conjunto edificado.

Porém, somente em 2017 o BNDES confirmou a liberação de R\$ 2 milhões do Programa "BNDES Procult", em recursos não reembolsáveis para o HESFA, na recuperação de benfeitorias e a serem geridos pela Fundação Universitária José Bonifácio, da UFRJ. Este projeto de intervenções emergenciais previa a recuperação das primeiras sete edificações construídas - todas tombadas inclusive com a recomposição de estruturas comprometidas e de varandas interditadas dos prédios 03 e 07 . Simultaneamente, seriam realizados serviços de descupinização, pintura, calafetagem, substituição de piso, recolocação de telhas e reestruturação da rede elétrica, estes investimentos foram enquadrados no objetivo de "incentivo da revitalização urbanística da região da Cidade Nova, no eixo que liga a Praça Onze ao Centro Administrativo São Sebastião".

Em complemento às intervenções, Bertolucci et al (2014) informaram que havia previsão para outra cota de financiamento, no valor de $\mathrm{R} \$$ 3,3 milhões provenientes de recursos próprios da UFRJ, além de uma terceira parcela, de R\$ 12 milhões, provenientes do Ministério da Educação através do Programa Nacional de Reestruturação dos Hospitais Universitários Federais (REHUF). Porém, no que tange os custos das obras necessárias, Rabello (2011) levantou que os financiamentos seriam insuficientes para reparo total das instalações, uma vez que seriam necessários cerca de $\mathrm{R} \$ 30$ milhões.

\section{Legislação}

Considerado o primeiro intento para a organização e a proteção do patrimônio artístico e cultural nacional, o Decreto-Lei $n^{\circ} 25$, de 30 de novembro de 1937, definiu o conceito da preservação de bens imóveis e móveis existentes no país, quando a conservação seria de interesse público.

Em 2013, Soares et al, indicaram que as ações práticas executadas em bens patrimoniais brasileiros nem sempre considerariam toda a magnitude intrínseca dos termos "restauração" e "conservação", e como bem expôs Kühl (2009), "a falta de diálogo entre as ações práticas e a teoria do restauro leva o patrimônio arquitetônico a uma situação de risco, pois se de um lado, faltam ações de manutenção preventiva, de outro, as intervenções realizadas, por vezes, estariam desprovidas de estrutura teórica própria do campo disciplinar do restauro".

Tais considerações podem conduzir ao entendimento que não há um embasamento teórico adequado e a improvisação utilizada por profissionais de reabilitação é frequentemente devida a pouca experiência e tradição na conservação do patrimônio histórico cultural brasileiro.

\section{Reabilitação Predial do Hospital Escola São Francisco de Assis (HESFA): Reconversação de Edifícios}

Apesar do tardio tombamento realizado em 1983, o prédio do Hospital Escola São Francisco de Assis (HESFA) não obteve a atenção adequada para receber os investimentos necessários no resguardo de suas características estéticas e históricas, ao longo dos anos. Com uma fachada principal em estilo arquitetônico neoclássico e disposição original pan-óptica, o conjunto sofreu diversas modificações ao longo do tempo, em anexos e na ampliação de espaços. Dos treze prédios integrantes do conjunto, edificados entre 1879 e 1920, ilustrados na Figura 01, não ocorreram intervenções expressivas na volumetria do projeto original.

Entretanto, com as intervenções irregulares ocorridas a partir de 1920, a tipologia inicial foi alterada para "elementos de qualidade arquitetônica bastante discutíveis" (Monteiro, 2014), como na interdição ou demolição das varandas e coberturas, que dariam unicidade ao conjunto, e a desativação de instalações prediais, substituídas por outras sem qualquer estudo de demanda de carga, provocando um grande risco ao conjunto edificado.

Sendo assim, o projeto de restauração do HESFA, em reportagem a Bertolucci et al (2014), objetivou, dentre outros aspectos, a reinterpretação do conjunto construído, entre 1920 e 1950, que foi em partes demolido, na reforma iniciada em 2012. Também, outras três edificações, erguidas após 1950, foram consideradas incompatíveis e fizeram parte do cronograma de obras. $\mathrm{O}$ escopo do projeto ainda incluiu a permanência daquelas benfeitorias com arquitetura condizente, assim como a reforma das varandas conectoras dos edifícios e o 
reestabelecimento das ligações interprediais, dentre outros. Igualmente, o Plano Diretor UFRJ 2020 prevê a construção de dois novos prédios, em salvaguarda da volumetria original.

É importante ressaltar que a aprovação de tais demolições foi feita pelo IPHAN, mediante análise da arquitetura de cada um dos prédios do conjunto e conclusão de sua incoesão. Neste aspecto, foram analisados os registros de construções contemporâneas, além da consulta a profissionais especializados no assunto para a decisão final.

Em adição, houve o restauro e a reabertura de um túnel subterrâneo que, em meados da década de 1920, conectava o conjunto à Escola de Enfermagem Anna Nery, do outro lado da Rua Afonso Cavalcanti. Outrora, o referido túnel foi construído para que as "moças de boa família" não tivessem que circular em horário tardio pela rua, tendo sido esta ligação desativada em 1978, com o início das obras do metrô.

\section{Patologias Encontradas e Intervenções}

Em entrevista a Rabello (2011), a vicediretora do HESFA, Prof. Maria Catarina Salvador, acusou as patologias estruturais como alarmantes e causas de grandes dificuldades para um melhor aproveitamento das instalações dos prédios do conjunto. De fato, Affonso (2012) ressaltou que, por este motivo, algumas áreas do conjunto foram desativadas, uma situação agravada pela ausência de qualquer manutenção preventiva e/ou corretiva nos últimos 40 anos de história do hospital.

Quando, das intervenções, os reforços estruturais foram muito necessários na recuperação das varandas dos prédios, como indicado na Figura 2, e nos ambientes internos, por vezes, houve a necessidade da total reconstrução dos elementos estruturais, completamente comprometidos pelo uso e ausência de manutenção preventiva, conforme indicado na Figura 3. Por outro lado, o acréscimo de cargas não dimensionadas no projeto estrutural original culminou no aparecimento de diversas deformações e, até mesmo, no rompimento de pilares. Por este motivo, foi necessária a demolição de alguns destes elementos postiços, como foi o caso das varandas posteriores (Figuras 4 e 5 ).
Figura 2 - Restauro do barroteamento e estrutura da varanda dos prédios 07 e 07A.

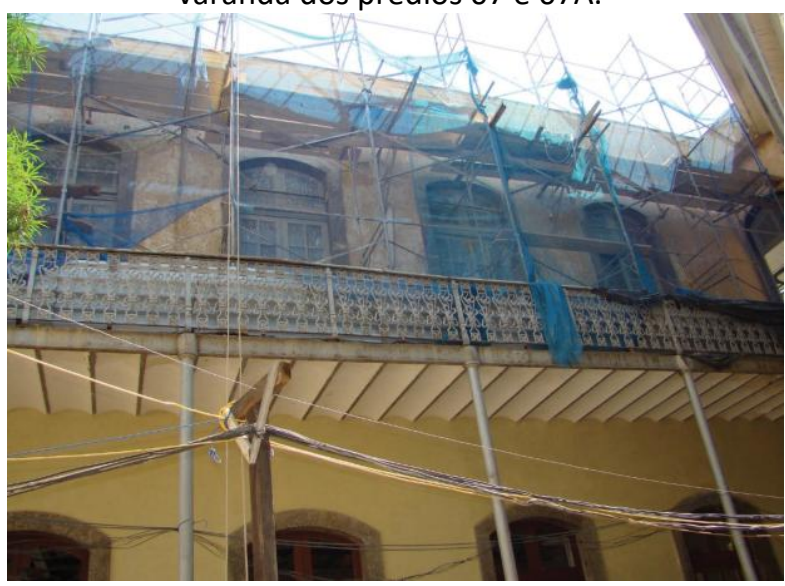

Fonte: ETU (2017)

Figura 3 - Restauro das vigas de madeira do segundo pavimento

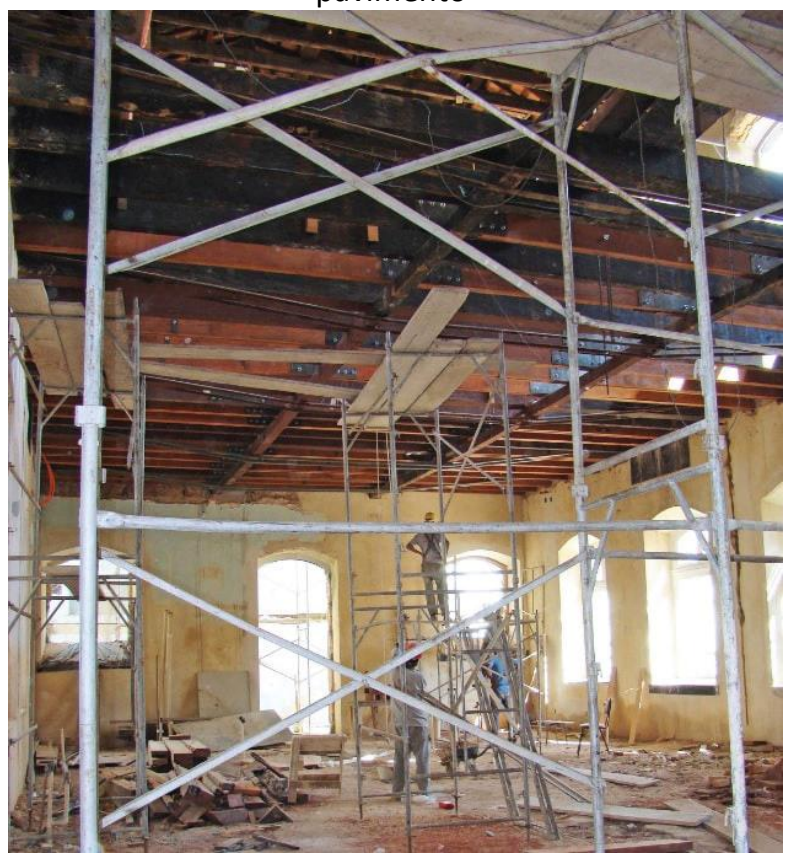

Fonte: ETU (2017)

Dentre as patologias causadas nas fundações, estruturas e vedações e elementos construtivos foram providenciadas intervenções para recuperar o conjunto. As Figuras 6 e 7 indicam desgastes severos, por excesso de umidade no madeiramento dos telhados, bem como a necessidade de substituição das telhas remanescentes. Em adição, esquadrias empenadas, instáveis e, até mesmo, com vidros ausentes/quebrados podem ser observados (Figura 10), assunto a ser abordado mais profundamente a seguir. 
Figura 4 - Demolição de varanda posterior do prédio 01.

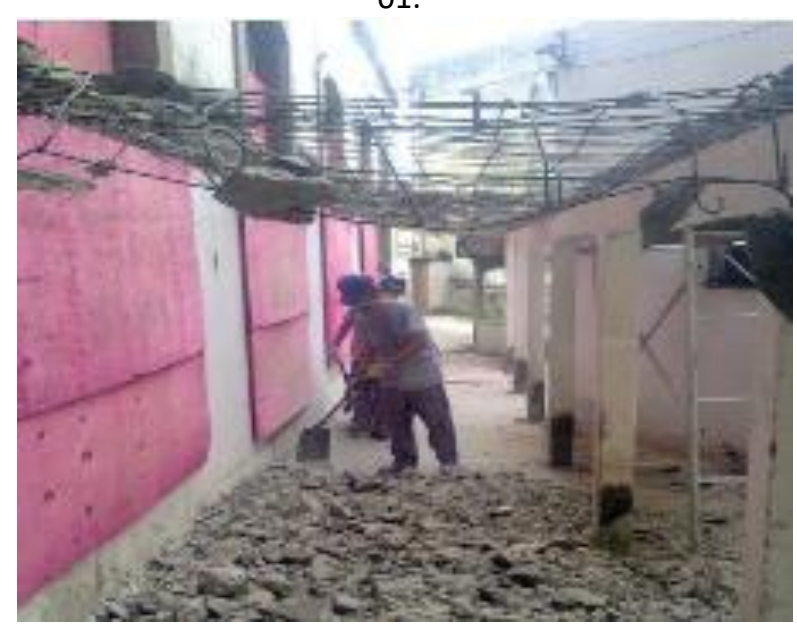

Fonte: ETU (2017).

Figura 5 - Demolição de estruturas da caixa d'água,cobertura do prédio 07.

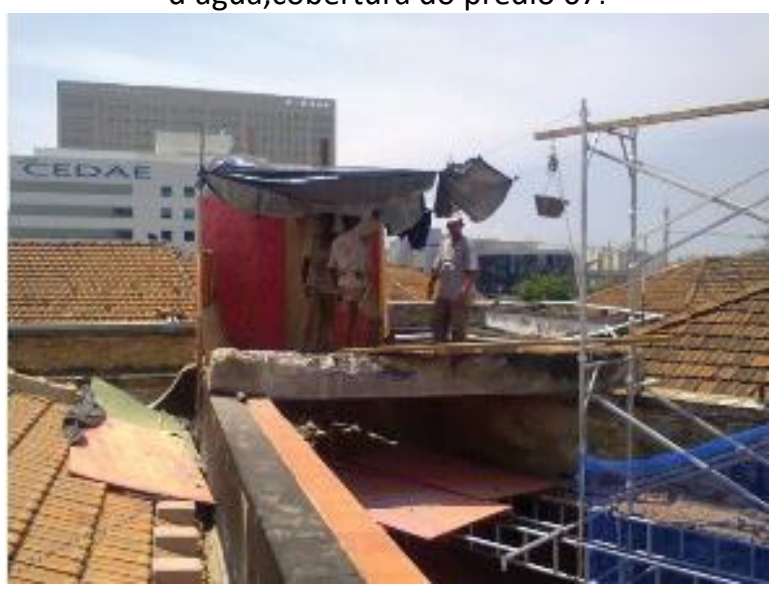

Fonte: ETU (2017)

Figura 6 - Recuperação total dos telhados.

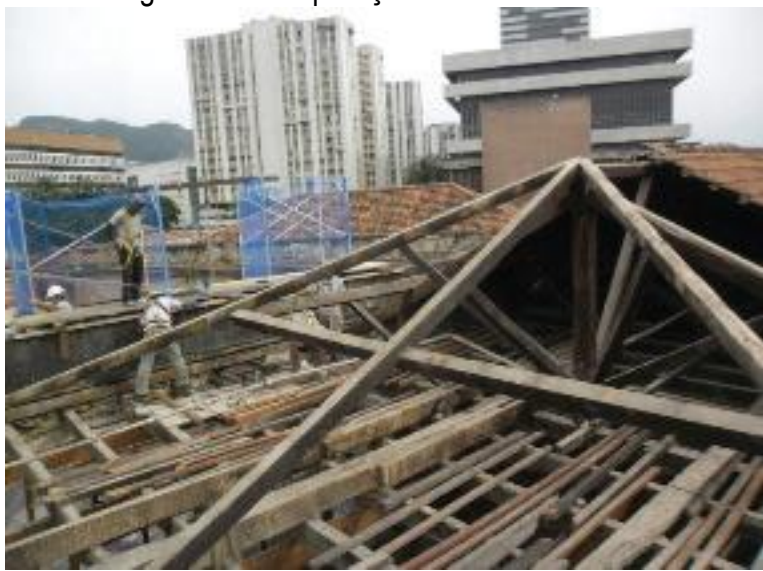

Fonte: ETU (2017)
Figura 7 - Tesoura comprometida, prédio 01

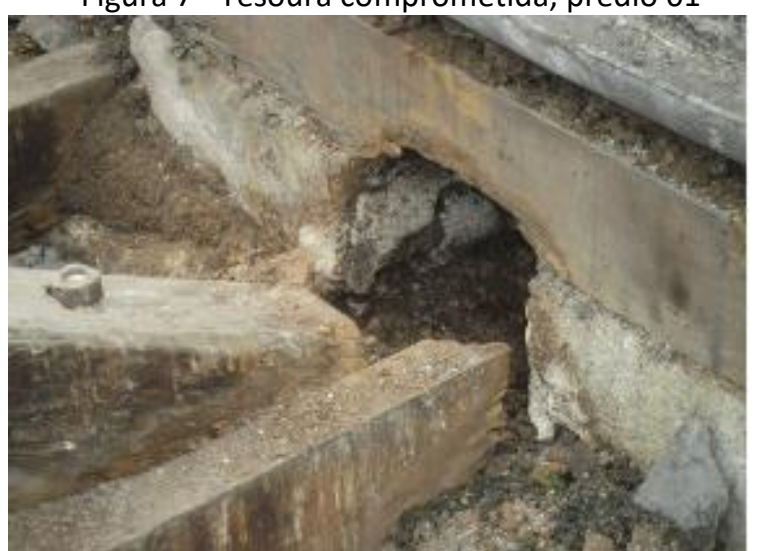

Fonte: ETU (2017)

Para a realização das intervenções consideradas necessárias para correção das patologias, o IPHAN solicitou comprovação de sua efetividade. Assim, foi necessária a execução de testes espectométricos, retirada de amostras para ensaios mecânicos e aberturas para verificação das condições nas benfeitorias existentes. Foi imperativo que todos os procedimentos fossem devidamente documentados e auditados, para comprovação das exigências técnicas das reabilitações.

\section{Recuperação e Manutenção de Áreas Degradadas}

Muitas são as intervenções necessárias para a adequada manutenção, conforme observado nas Figuras 8 a 11, além de outros temas como a colocação de lajotas, o fechamento de vãos de janelas não pertencentes ao projeto original e outros.

Dentre as referidas, cita-se aqui a obra licitada e já concluída para a restauração dos prédios 01 a 06, primeira etapa prevista no Plano Diretor aprovado para recuperação do conjunto. Nela é prevista a retirada de árvores enraizadas nas paredes externas, recuperação de condições estruturais (Figura 12). Rachaduras, telhados, varandas e fachadas destes prédios (Figura 13). Neste mesmo escopo, ainda constava a demolição de edificações posteriores e alguns elementos espúrios que supostamente traziam prejuízos à "apreensão da configuração original" (ETU, 2017). A segunda etapa concebe a restauração dos prédios 07 e 07A - por descontinuação dos pagamentos às empresas contratadas para realização dos serviços.

Rabello (2011) também destacou que quase todos os blocos originais do conjunto encontram- 
se em estado precário de conservação, sendo que alguns destes interditados. Apesar de indícios de obras de recuperação em alguns dos blocos e de, acordo com relatado à CEPC-CMRJ, a execução de um Plano Diretor de recuperação de todo o conjunto, o processo iniciado em 2013 apresenta constante interrupção das obras, causadas por recorrentes cortes nos financiamentos.

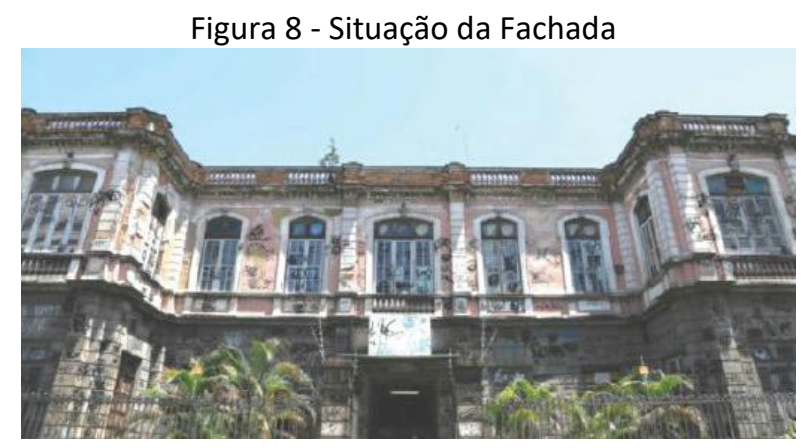

Fonte: Cavalcanti (2013) apud Monteiro (2014)

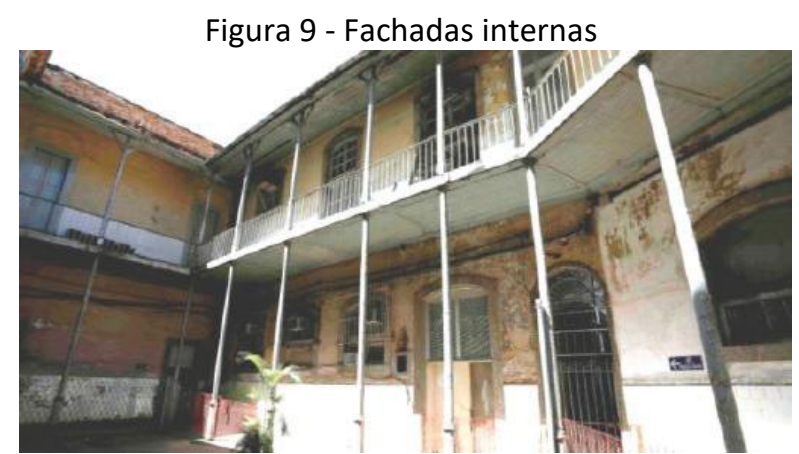

Fonte: Cavalcanti (2013) apud Monteiro(2014)

Figura 10 - Esquadrias e vidros danificados

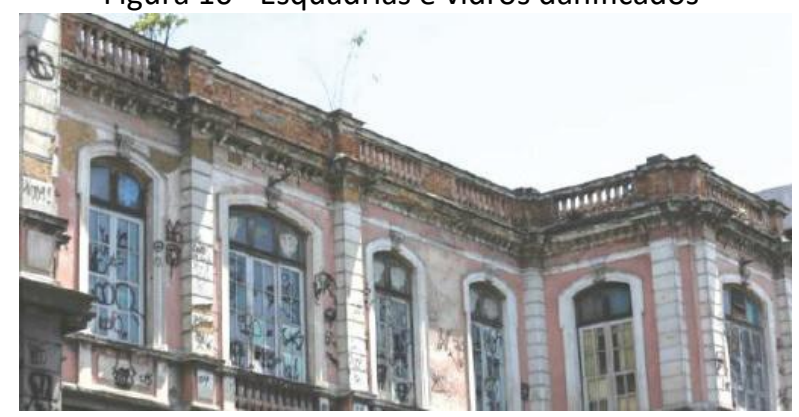

Fonte: Cavalcanti (2013) apud Monteiro (2014)

Figura 11 - Partes em ruínas de prédios

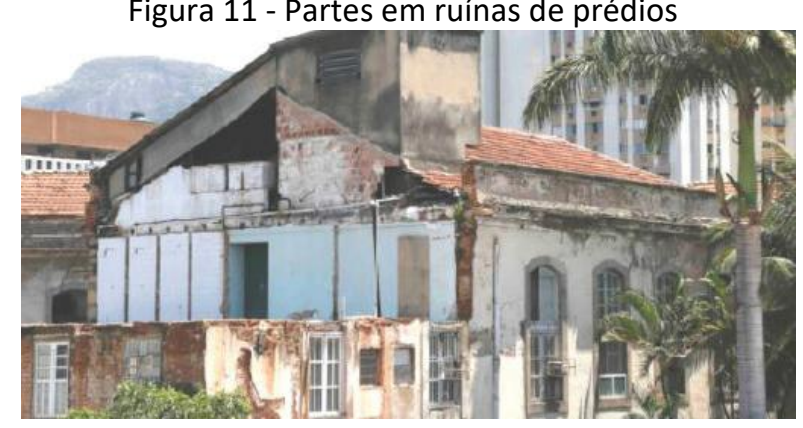

Fonte: Cavalcanti (2013) apud Monteiro (2014)
Figura 12 - Reconstituição de assoalho danificado

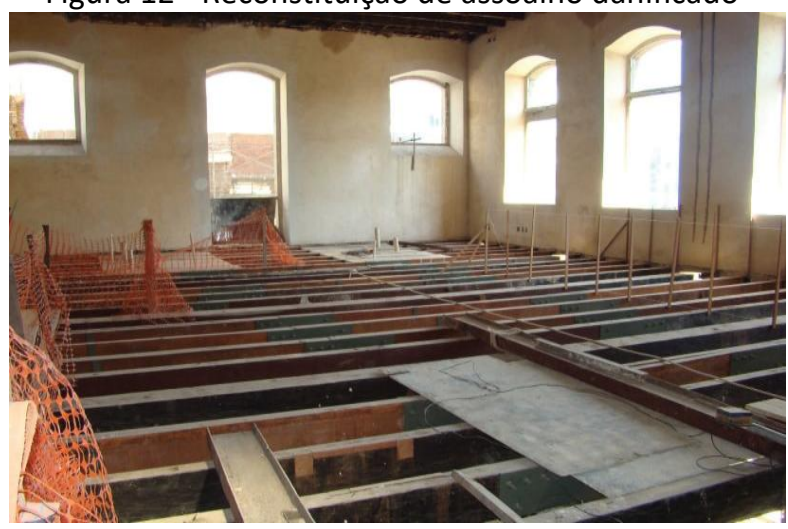

Fonte: ETU (2017)

Figura 13 - Recuperação dos revestimentos da varanda dos prédios 01 e 03

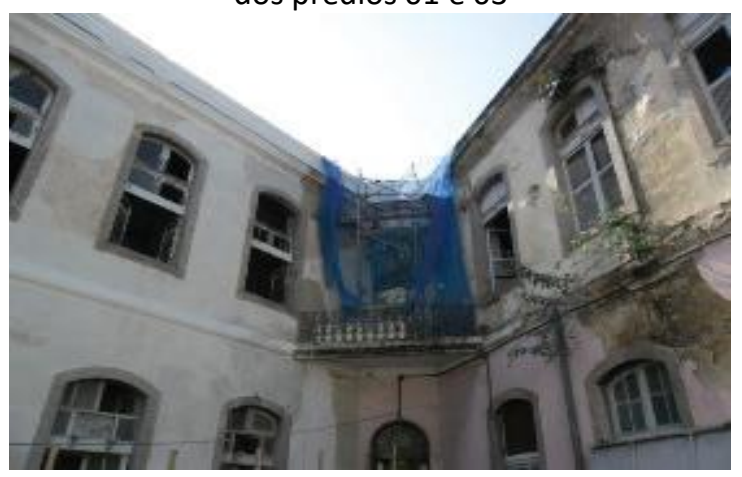

Fonte: ETU (2017)

Ademais, conforme exposto anteriormente, a recuperação de determinados elementos - como - assoalho danificado da Figura 12 - foi dificultada dadas as exigências solicitadas pela IPHAN. Por vezes, as especificações demandavam a substituição de materiais atualmente inacessíveis, uma vez resguardados por legislação ambiental. A substituição por outro somente é autorizada pelo órgão federal após análise da efetiva similaridade arquitetônica e estética do novo material. Tal processo usualmente é lento e desencorajador.

\section{Considerações Finais}

A preservação de edifícios tombados é, indubitavelmente, um dos meios mais efetivos para a conservação da história de uma cidade e de seus habitantes, pois reflete a evolução das adaptações necessárias para a vivência através das diferentes épocas, além do testemunho de diversos movimentos estéticos, de arquitetura e de arte. Assim, a restauração de edifícios antigos é um meio de preservação de valores culturais, além de ambientalmente preferível, uma vez que 
as emissões de gases e geração de resíduos sólidos da construção civil seriam mitigadas.

A sistematização da manutenção programada para uma restauração preventiva pode ser um método mais eficiente para a manutenção de uma edificação histórica. Contudo, por vezes, a prática é inviabilizada, seja pela escassez de recursos ou pelos obstáculos burocráticos impostos, inviabilizando a promoção de intervenções necessárias, ocorrendo também a ambiguidade permitida na legislação disponível atualmente, o que provocou as interrupções recorrentes e dificuldades desmotivadoras aos profissionais e entidades envolvidas no HESFA.

Desta forma, é essencial a revisão das legislações, normas e diretrizes para que ocorra a preservação por uma equipe multidisciplinar que, inclusive, vise à destinação de uma fração pré-determinada - e posteriormente auditada - de recursos destinados à sua preservação. Ainda, nas intervenções mais invasivas, deve haver a autorização efetiva da necessidade e da ausência de alternativas, como uma boa prática na viabilização da conservação de edificações tombadas.

\section{Agradecimentos}

Ao Escritório Técnico da Universidade (ETU/ UFRJ), pela disponibilização de dados na restauração do HESFA.

\section{Referências}

MONTEIRO, F. A. O Abandono do Monumento: $O$ Caso do Hospital Escola São Francisco de Assis. Revista do Colóquio de Arte e Pesquisa do PPGA-UFES, ano 4, v. 3, n. 6, 2014, pp. 47-64.

SOUZA, M. V.; RIBEIRO, R. T. Hospital São Francisco de Assis: Diretrizes de Projeto. Anais do XI Congresso da ABRACOR, 2002, pp. 130-131.

KÜHL, B. M. Arquitetura do Ferro e Arquitetura Ferroviária em São Paulo: Reflexões sobre a sua Preservação. São Paulo: Secretaria da Cultura, FAPESP, Ateliê Editorial, 1998.

RABELLO, S. Hospital Escola São Francisco de Assis ou Crônica de um Descaso. 2011. Disponível em:<http:// www.soniarabello.com.br/hospital-escola-saofrancisco-de-assis-ou-cronica-de-um-descaso/>. Data de acesso: 30 de Novembro de 2017.

BERTOLUCCI, R., LIMA, L., CANDIDA, S. Colando os Cacos de 135 Anos de História. Jornal O GLOBO, Caderno Design Rio, 01/06/2014, p. 24.

UNIVERSIDADE FEDERAL DO RIO DE JANEIRO, UFRJ. Plano Diretor UFRJ 2020, 2009. Disponível em:<https://ufrj.br/

docs/plano_diretor_2020/PD_2011_02_07.pdf>. Data de acesso: 30 de Novembro de 2017.

BANCO NACIONAL DO DESENVOLVIMENTO, BNDES. BNDES apoia com R\$̦ 2 milhões restauração do Hospital Escola São Francisco de Assis (RJ). 16 de Fevereiro de 2011. Disponível em:<https://www.bndes.gov.br/wps/portal/ site/home/imprensa/noticias/conteúdo/2011021 6_hesfa>. Data de acesso: 30 de Novembro de 2017.

SOARES, I. S. R, OLIVEIRA, C. T. A. Preservação Arquitetônica: teoria, legislação e prática. Revista CPC, n. 15, 2013, pp. 137-162.

RABELLO, S. Entrevista Exclusiva com a Vice Diretora do Hesfa. 2011. Disponível em:<http://www.soniarabello.com.br/ entrevista-exclusiva-com-a-vice-diretora-dohesfa-e-professora-maria-catarina-salvador/>. Data de acesso: 30 de Novembro de 2017.

AFFONSO, J. Tombados como patrimônio nacional, imóveis históricos do Rio sofrem com degradação e abandono. Disponível em:<https://noticias.uol.com.br/cotidiano/ ultimas-noticias/2012/12/17/tombados-comopatrimonio-nacional-imoveis-historicos-do-riosofrem-com-degradacao-e-abandono. htm\#fotoNav=3>. Data de acesso: 30 de Novembro de 2017.

ESCRITÓRIO TÉCNICO DA UNIVERSIDADE, ETU/UFRJ. Acervo da Restauração dos Prédios 07 e 07A. Disponível em:<http://www.etu.ufrj.br/siaci/imagem_from_ obra/3>. Data de acesso: 01 de Dezembro de 2017.

*Camilla de Abreu e Silva é engenheira civil e mestranda do Programa de Engenharia Urbana (PEU/UFRJ). 